UCID - 16622

This is an informal report intended primarily for internal or limited external distribution. The opinions and conclusions stated are those of the author and may or may not be those of the laboratory.

\author{
L5 \\ LAWRENCE LIVERMORE LABORATORY \\ University of California/Livermore,California \\ HANDY GUIDE TO THE PRESHOT ANALYSIS
FOR INTEREEROMETRIC MEASUREMENTS
}

Minao Kamegai

April 4, 1974

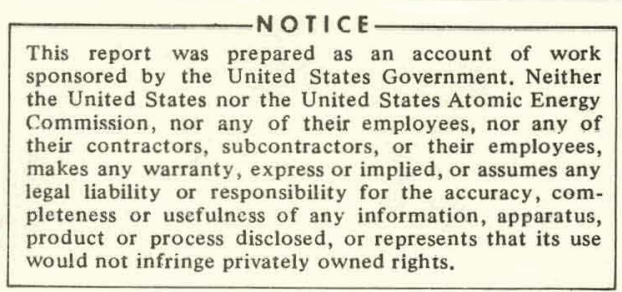

Prepared for U.S. Atomic Energy Commission under contract no. W-7405-Eng-48 


\section{DISCLAIMER}

This report was prepared as an account of work sponsored by an agency of the United States Government. Neither the United States Government nor any agency Thereof, nor any of their employees, makes any warranty, express or implied, or assumes any legal liability or responsibility for the accuracy, completeness, or usefulness of any information, apparatus, product, or process disclosed, or represents that its use would not infringe privately owned rights. Reference herein to any specific commercial product, process, or service by trade name, trademark, manufacturer, or otherwise does not necessarily constitute or imply its endorsement, recommendation, or favoring by the United States Government or any agency thereof. The views and opinions of authors expressed herein do not necessarily state or reflect those of the United States Government or any agency thereof. 


\section{DISCLAIMER}

Portions of this document may be illegible in electronic image products. Images are produced from the best available original document. 


\title{
HANDY GUIDE TO THE PRESHOT ANALYSIS \\ FOR INTERFEROMETRIC MEASUREMENTS
}

\begin{abstract}
Two methods of preshot analysis for measurements which require a laser Doppler interferometer are described. Both methods have the same goal. Prior to the experiment, the velocity history to be measured is calculated using the best available data on the material. Then the calculated velocities are translated into an interferometric fringe pattern. Such an approach to interferometric measurements is very useful when one attempts to measure complex velocity profiles where the frequency of the signals to be recorded varies greatly during the measurement. In such an experiment, the frequency can often exceed the bandwidth of the photomultiplier. By making the preshot analysis of the interferometric data, one can avoid the risk of losing important data by properly adjusting the interferometer before the experiment. An example is given to demonstrate the usefulness of both methods.
\end{abstract}

\section{INTRODUCTION}

This note describes convenient methods of preparatory analysis for the interferometric data when the measurement requires a laser Doppler interferometer. A serious limitation placed on the laser interferometer is the bandwidth or the response characteristics of the photomultiplier which is an essential component of the interferometer. When the frequency of the signals to be measured exceeds the bandwidth of the photomultiplier the resultant data are incomplete, in which case the experimenter fills in the missing data with his "intelligent guess." To compound the difficulty, the frequency of the signal is not uniform during the measurement. Usually one observes a burst of signals upon the arrival of a shock wave followed by no signal during a period of constant velocity. At a later time, a release wave again brings low-frequency signals.

The signal frequency can be adjusted before the measurement by properiy setting the adjustable optical delay on the interferometer if we have some prior knowledge of the velocity history to be measured. The optical delay is set so that the most important segment of the data is completely recorded, thus making a compromise on the remaining portion of the data. We have developed convenient methods to fulfill this objective.

The first method described in this report is a two-step process. First, the velocities of the surface to be measured are calculated for a given experiment with a $\mathrm{B}$-Division code, KO, using the best available cquation-of-state. The calculated 
velocities are written out on a tape. The second step is the conversion of the velocities into the interferometric data; i.e., a fringe pattern. This will provide the crucial information on the frequencies of the signals that the experimenter can expect during the measurement.

This kind of approach to interferometric measurements is particularly important when we attempt to measure complex velocity profiles such as we observe in hydroexperiments. For this purpose, we developed the second method. Taking the old data on the velocity history for a similar hydro-experiment; e.g., a streak record, we crudely digitize the velocity-versus-time plot. Then the velocity history is translated into the interferometric data.

These methods were tested and proved to work very well. The computer programs are attached at the end of the report for the convenience of the users.

\section{FROM KO CALCULATION TO FRINGE PATTERN}

Step 1

The first step is a $\mathrm{KO}$ calculation of the velocities, This requires a proper problem deck. The KO-problem deck is preceded by the following control cards:

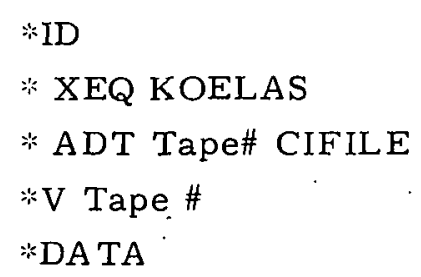

The standard KO input is used to set up all the problem except the $\mathrm{J}$-number of the surface where the velocities are being calculated. The $\mathrm{J}$-number is given by an input variable, MKU, according to the following rules:

1. $M K U=$ Positive Integer

MKU is the $J$-number of the outermost zone; i.e., the free-surface of the target where the velocities are being calculated. Note that MKU $=$ Total Number of Zone +1

2. $M K U=$ Negative Integer High-pressure measurements often require an optical window in contact with the free surface where the velocities are interrogated. In this case, MKU is the region number of the optical window given by a negative integer. The velocities are calculated at the inner boundary of the region.

The calculated velocities are written onto a tape as file CIFILE. 
The second step is the translation of the velocities into a fringe pattern. The operation is performed by an interactive program CALCI. The program CALCI is stored in the photostore in the directory, .FCALCI. CALCI performs the conversion of the velocities into a fringe pattern by the following equation ${ }^{1}$ :

$$
\begin{aligned}
& \text { For } 0 \leq t \leq \tau \\
& I=A \cos ^{2}\left(\phi_{0}+\frac{2 \pi t U}{\lambda}\right) \\
& \text { for } \tau<t \\
& I=A \cos ^{2}\left(\phi_{0}+\frac{2 \pi \tau U}{\lambda}\right)
\end{aligned}
$$

where $\tau$ is the light transit time along the optical delay.

It is probably most instructive if the entire operation on a teletype is explicitly described showing the input messages by arrow signs. The operation is as follows:

1. To read the calculated velocities

$\rightarrow$ Ask operator for Tape \#

[OK]

$\rightarrow$ RDFILES Tape \# CIFILE / T V

ALL DONE

2. To read out CALCI from the photostore

$\rightarrow \mathrm{ELF} / \mathrm{T} \mathrm{V}$

$\rightarrow$.RDS .FCALCI:CALCI

$\because R D S$

$\rightarrow$ END

ALL DONE

3. To convert the velocities into a fringe pattern:

$\rightarrow \mathrm{CALCI} / \mathrm{T} \mathrm{V}$ BOXAAA ID

- BOXC61 M. KAMEGAI COMPILED - 02/12S 14.34.54 RUN - 15:01:26S 02/12/74 TYPE INPUT - N59 XN.XM YN YM AI TOI VI X1I GI YCI VMIN (see footnote 1) ?

$\rightarrow \quad 0$ 0. 1. -3.2. $-1.0 .3 . E 42.05$ 156. .5268 2.E-4

$$
0 \text { 0. } 1 \text {. } \quad-3 \text {. } 2 \text {. }
$$

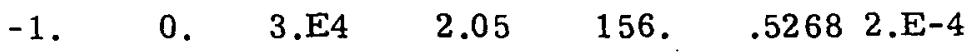

TYPE YES OR NO (see footnote 2)

$?$

1. M. Kamegai, Analysis of a Laser Doppler Interferometer, UCRL-75452-ppt, February 9, 1974 (submitted to Applied Optics Letters). 
$\rightarrow$ YES

CIFILE GENERA TED - $23: 06: 21 \quad$ T02/11/74

D3819B

TIME 1.4153398 TAO $=5.13167 \mathrm{E}-03$ (see footnote 3)

SCALE CHANGE (see footnote 4)

?

$\rightarrow$ YES

XN XM YN YM

?

$\rightarrow 0$. $.6-3$. 2 .

$0 . \quad .6 \quad-3 . \quad 2$.

$\mathrm{OK} ?$

$\rightarrow$ OK

SCALE CHANGE

?

$\rightarrow \mathrm{YES}$

$X N \quad X M \quad Y N \quad Y M$

?

$\rightarrow \quad .3 \quad .6 \quad-3 . \quad 2$.

3. $\quad .6 \quad-3 . \quad 2$.

OK ?

$\rightarrow \mathrm{OK}$

SCALE CHANGE

?

$\rightarrow \mathrm{NO}$

ALL DONE

FOOTNOTES:

1. Definition

N59 $=1$ Type all the velocities and times on the teletype.

$=0$ Do not type the velocities and times on the teletype.

$\mathrm{XN}=$ Minimum scale for time.

XNI = Maximum scale for time

$\mathrm{YN}=$ Minimum scale for amplitude

YM = Maximum scale for amplitude

AI $=$ Fringe amplitude

TOI $=$ Initial phase $\phi$ (in radian)

VI $=$ Velocity of light (in $\mathrm{cm} / \mu \mathrm{s})$

$\mathrm{X} 1 \mathrm{I}=$ Reference path (in $\mathrm{cm}$ )

$\mathrm{GI}=$ Delay path (in $\mathrm{cm}$ )

$\mathrm{YCI}=1 / \lambda \mathrm{C}$

VMIN = Cut-off velocity

2. YES means that the teletype agrees with the input quantities.

NO means that the teletype does not agree with the input.

3. TIME = Time when the surface began to move.

$\mathrm{TAO}=$ Light transit time along the optical delay.

4. SCALE CHANGE allows the enlargement of a segment of the fringe pattern. Both amplitude and time scales can be changed. 
The results are written into a DX-file which can be viewed on a screen and sent out to either RJET or CRT by the following method:

1. To send to RJET as it is displayed on a screen:

$\rightarrow$ EXE HEED DDTVRJ DR. / T V ALL DONE

$\rightarrow$ DDTVRJ Screen \# / T V TYPE DD80 FILENAME

$\rightarrow$.DX-file

$\rightarrow$.S 5 (skip 5 pages)

$\rightarrow$.RJ TYPE RJET\# BOX AND ID

$\rightarrow$ \# BOX C61 M. KAMEGAI

$\rightarrow$.END

ALL DONE

2. To send to CRT:

$\rightarrow$ GIVE DX-file 999999 / T V OK

$\rightarrow$ END

\section{ALL DONE}

The source program for CALCI is called CICAL, which is attached at the end of the report.

Figure 1 shows an example. The free-surface velocities were calculated for an aluminum impact experiment at $13 \mathrm{~kb}$ prior to the measurement. The velocity history is displayed, together with the predicted fringe pattern and the actual interferometric data. This example clearly demonstrates the usefulness of the method.

\section{FROM HYDRO-VELOCITY HISTORY TO FRINGE PATTERN}

This method is a crude preshot analysis of the interferometric data for hydroexperiments. Taking the old data on a similar hydro-experiment, we digitize the velocity history. In analyzing a very complex velocity profile which is characteristic to hydro-experiments, accuracy required on timing greatly varies over the velocity plot. Thus, in digitizing the velocity history, varied interval times are taken in different regions of the plot.

F.urthermore, the pressures achieved in hydro-implosions are quite extraordinary. This imposes very severe requirements on instrumentation. The most suitable 

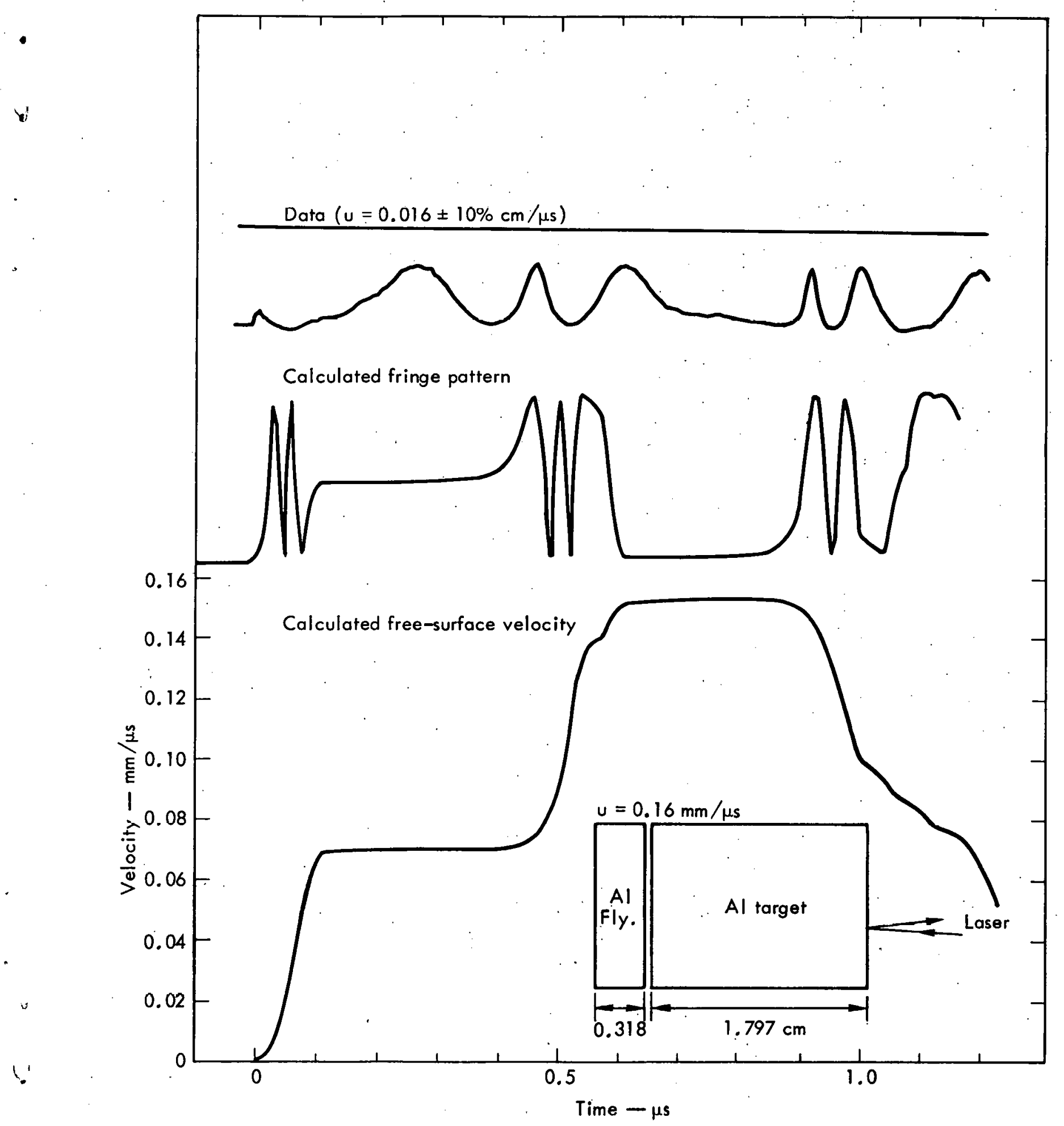

Fig. 1. An example of the calculated fringe pattern. 
interferometer for this type of measurement is a diffuse Doppler interferometer. Since the diffuse interferometer characteristically operates on a complex optical delay path, all the components of the optical delay must be considered in calculating the light transit time through the delay path.

The deck we prepare after the velocities have been digitized is called INPUT. INPUT-deck consists of an ID-card followed by all the input quantities. END-card marks the end of the deck. Each card may contain any number of input quantities or input variables. Only one space is required between any two adjacent numbers or variables. INPUT-deck is arranged in the following order

IDU458850 INPUT

$\mathrm{V} 1=2.2 .3 \quad 2.71$ etc.

$\begin{array}{llll}4.21 & 4.4 & 4.62 \quad \text { etc. }\end{array}$

$\mathrm{V} 2=6.2 \quad 6.7 \quad 6.91 \quad \mathrm{~V} 3=7.21 \quad 7.3 \quad$ etc:

$\mathrm{DTL}=.01 \quad \mathrm{DT} 2=.5 \quad \mathrm{DT}=.01 \quad$ etc.

$\mathrm{VC}=.1 \quad \mathrm{~A}=-1 . \quad$ PHIO $=0 . \quad$ etc.

$\cdot \quad \cdot$

$\cdot$

END

The code which translates the digitized velocities into a fringe pattern is called FRINGE. The fringe pattern is calculated by ${ }^{1}$

$$
I=A \cos ^{2}\left(\phi_{0}+\frac{2 \pi \tau U}{\lambda}\right)
$$

where $\tau$ is the light transit time through the delay:" FRINGE is run by the ORDER system. It reads the file INPUT for data.

The operational procedure is as follows:

Read FRINGE in a 7600

Read INPUT in a 7600

Operate by a standard method,

ORDER FRINGE / $T$ V.

\footnotetext{
"Definition

$\mathrm{V} 1, \mathrm{~V} 2, \mathrm{~V} 3, \mathrm{~V} 4, \mathrm{~V} 5=$ Velocities in arbitrary unit in regions $1,2,3,4$, and 5 . DT1, DT2, DT3, DT4, DT5 = Time steps taken in regions $1,2,3,4$, and 5 .

$A=$ Fringe amplitude (usually -1. )

PHIO = Initial phase (radian)

$\mathrm{XR}=$ Total reference path $(\mathrm{cm})$

$\mathrm{XE}=$ Total path through etalon $(\mathrm{cm})$

$X A=$ Total path through air space $(\mathrm{cm})$

$\mathrm{XQW}=$ Total path through $\lambda / 4$-plate $(\mathrm{cm})$

$\mathrm{XBS}=$ Total path through beamsplitter $(\mathrm{cm})$

$\mathrm{RIE}=$ Etalong refractive index

$\mathrm{RIQ}=\lambda / 4$-plate refractive index

RIB = Beamsplitter refractive index

WLAM $=$ Wavelength $(\mathrm{cm})$

$\mathrm{VC}=$ Factor to convert the velocities into $\mathrm{cm} / \mu \mathrm{s}$.
} 
The result is written into a DX-file which can be viewed on a screen and sent out to either RJET or CRT. The program FRINGE is attached at the end of the report.

\section{SUMMARY}

The methods of the preshot analysis for interferometric measurements can be outlined as follows:

1. From KO-calculation to Fringe Pattern

Step 1

Prepare a KO-problem deck for the experiment, and calculate the velocities of the surface to be interrogated. The deck must include the special control cards ( $s$ tar cards) and a special input (MKU). The calculated velocities are written onto a tape as file CIFILE.

Step 2

Read out CALCI from the appropriate storage. Read CIFILE from the tape. Perform the conversion of the velocities into a fringe pattern by a standard method, CALCI / T V.

2. From Hydro-velocity to Fringe Pattern

Crudely digitize the velocity history of a similar hydro-experiment. Prepare INPU T-deck which comprises the digitized velocities and all the input quantities. Read in INPUT and a program FRINGE separately. Perform the conversion of the velocities to a fringe pattern by the ORDER system; i.e.,

ORDER FRINGE / T V.

This report is merely intended to be a handy guide to the preshot analysis of interferometric measurements. However, we clearly demonstrated the usefulness of the methods described in this report. Perhaps the individual experimenters should further explore such an approach to the experiment.

\section{ACKNOWLEDG MENTT}

S. J. French, Jr. wrote the computer programs. 


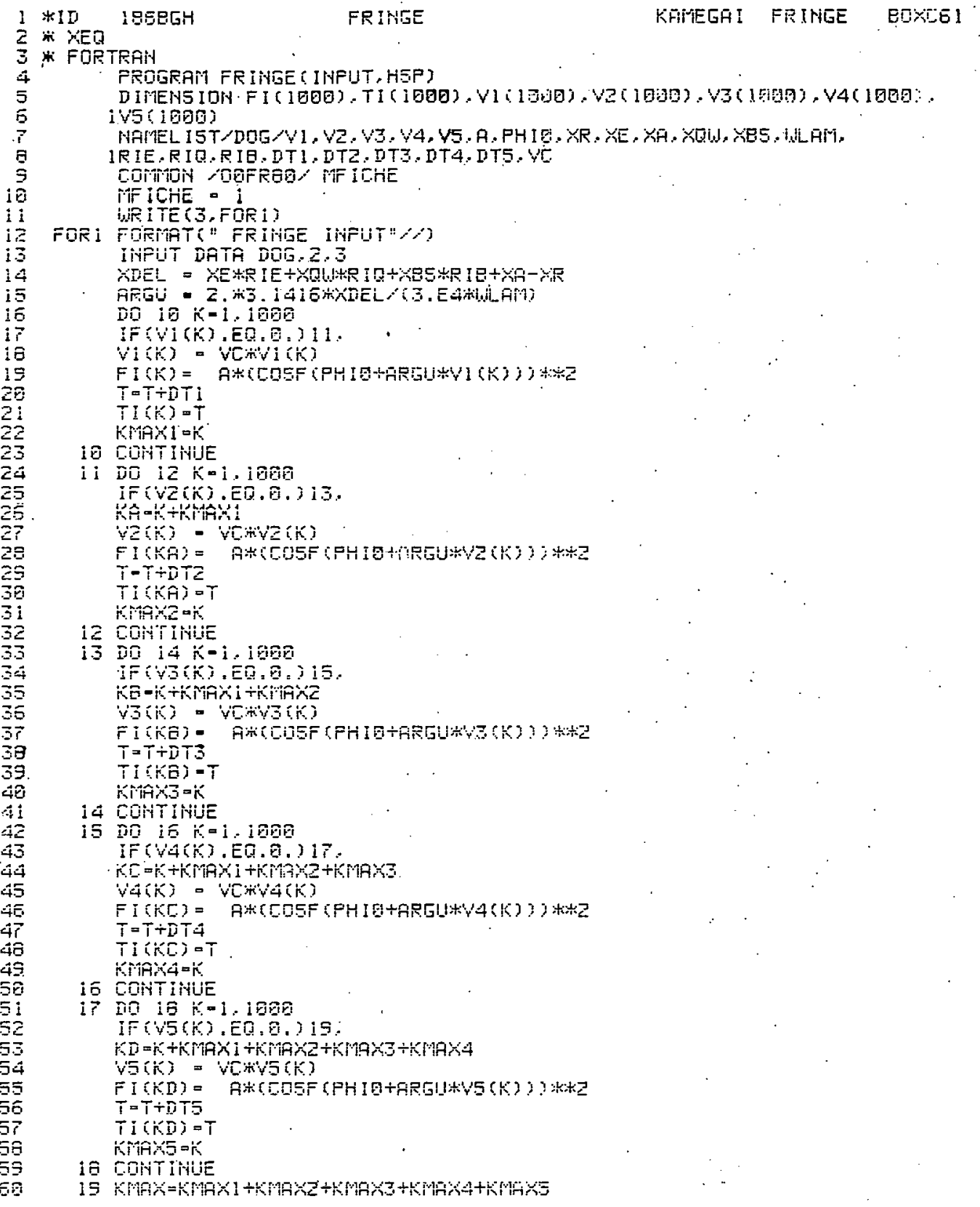

is

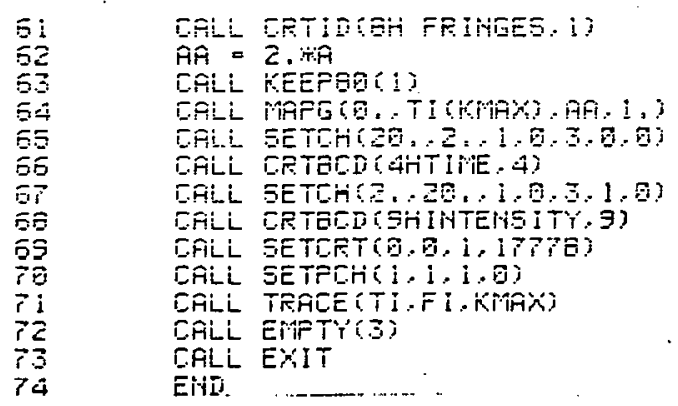




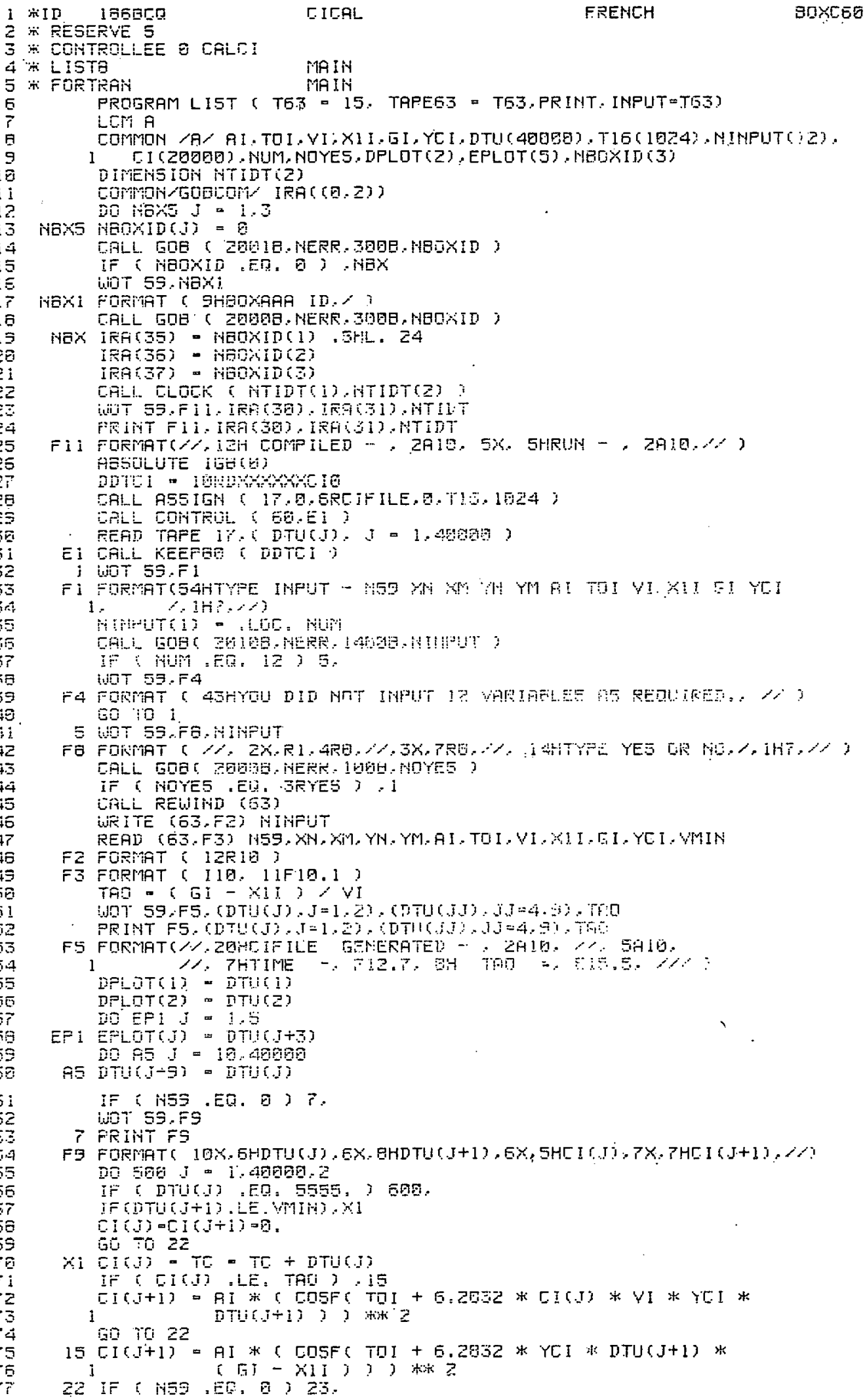




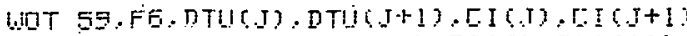

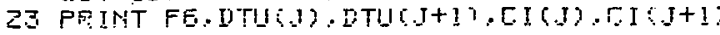

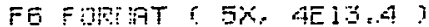

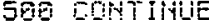

600 ifi $1=J-1$

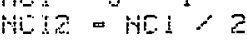

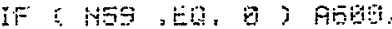

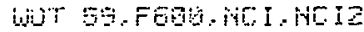

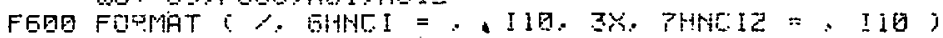

AEOD EALL ERTI

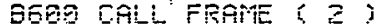

FALL SETERT \& $1,1,1.1,0$ ?

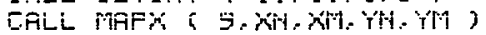

EALL SETEH i.. 20.. 1.日.2.1.)

HIT IOF FPA DFLOT

FFA FDRMAT\&ZZH UE IFILE GENERATED - . ZA10)

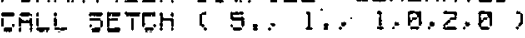

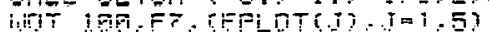

Tr Fin

EAL TRAEE

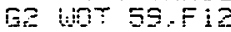

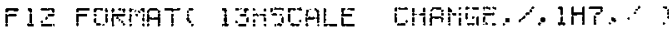

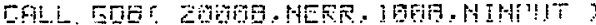

IF C HINPUT E ER. GRYES? G1.

IF i MINPIT ER, ZRND ? 5.5.

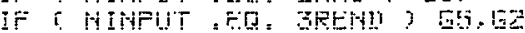

Gi LOT 59.FGi

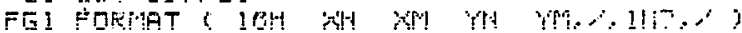

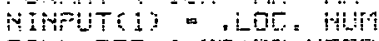

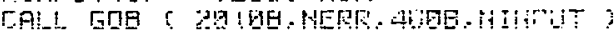

iF a Min $=0,4$ ?

int 59.692

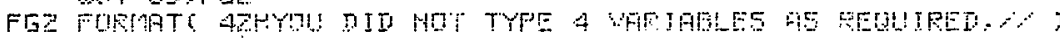
50

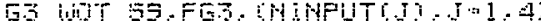

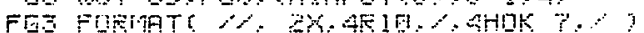

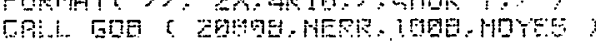

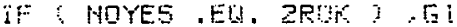

REIIVD 663

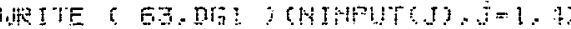

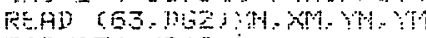

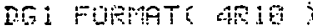

DGE FOEMTT i ATH 1 i

60 To 0600

5 CRLLL PLOTE

CALL EMIT

RETURT

Eivi

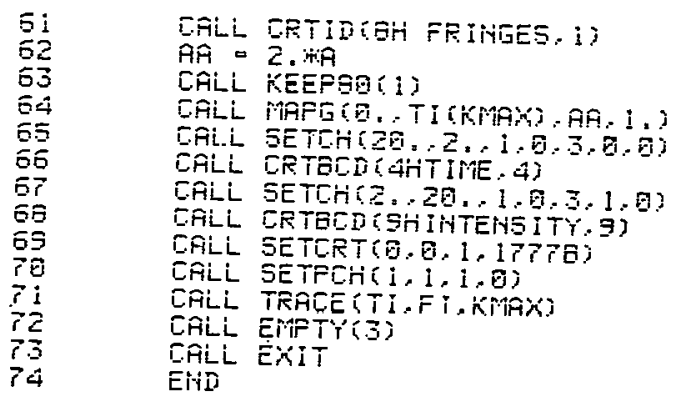




\section{DISTRIBUTION}

\section{IIL Internal Distribution}

TID File

M. Kamegai, L-504

\section{External Distribution}

W. Hollander

Institut fur Aerobiologie

W. Germany

U. S. Atomic Energy Commission, TIC, Oak Ridge, Tennessee

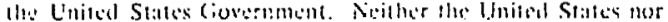
the Uniled States Aomide lineryy Commissim, nor any of the ir cmployese nor any of their contractors, sulncontracturs, or their employes. nor any of their contractors, subcontractors, or their any kejal liability or responsibility for tlk aceuracy, completeness or use tuhness of any information. anparatts, product or process disclostel or represents that its ase would not intringe privately. owitud riphis." 